\title{
Some Factors that Influence Doctor-Patient Relationship on Effective Healthcare Delivery in Some Public Health Care Facilities in Ogbia Local Government Area of Bayelsa State, Nigeria.
}

\author{
Tawari Erebi Patricia ${ }^{a}$, Boloya Vukumo Eric ${ }^{\mathrm{a}}$ \\ aperebi8@yahoo.com \\ ${ }^{a}$ Department of Chemical APthology, Faculty of Basic Medical Sciences, College of Health Science, Niger Delta Univerisity, Bayelsa State, \\ Nigeria
}

\begin{abstract}
Background: Trust is a fundamental characteristic of the physician-patient relationship. Patients must trust that their physicians will work in their best interests to achieve optimal health outcomes. The quality of relationship between doctors and patients in government hospitals is fundamental for the several outcomes as regard services rendered by the doctor and those received by the patients and in other to improve the quality of healthcare delivery in public health care sector. The study conducted to determine some factors that can influence of doctor-patient relationship which would eventually determine the effectiveness of health care delivery in public health centres in Ogbia, Bayelsa State, Nigeria.

Methods: A descriptive cross-sectional study design was conducted among patients in Federal Medical Center, Otuoke, General Hospital, Kolo and Cottage Hospital, Otuasega, all in Ogbia Local Government Area of Bayelsa state. Data collection was carried out using both self-administered and interview administered questionnaire. 138 patients were selected for the study. An average of 20 interviews were conducted per clinic day.

Results: Numerous factors such as age, gender, level of education, socioeconomic status, cultural and religious beliefs can affect physician-patient relationship. Results of this study demonstrated that communication and trust were the two most pivotal factors that greatly influenced the effectiveness of health care delivery and many patients were satisfied with the services received from their doctors.

Conclusion: Communication and mutual trust between the doctor and patient are of the major factors that influences doctor patient relationship.
\end{abstract}

Key words: Doctor-Patient relationship; Health care delivery; Public Health Care Facilities; Communication; Trust.

\section{INTRODUCTION}

Doctor-Patient Relationship can be referred as a consensual relationship in which the patient knowingly seeks the physician's assistance and in which the physician knowingly accepts the person as a patient (Szasz and Hollender 1956; Dwolatzky et al., 2006). The physician-patient relationship is the foundation of clinical care. Physician-patient relationship can have profound positive and negative implications on clinical care. Ultimately, the overarching goal of the physician-patient relationship is to improve patient health outcomes and their medical care. Stronger physician-patient relationships are correlated with improved patient outcome. As the relationship between physicians and patients becomes more important, it is essential to understand the factors that influence this relationship. Patients sometimes reveal secret worries and fears to physicians that they have not yet disclosed to friends or family members. Placing trust in a doctor helps them maintain or regain their health and wellbeing (Helin, 2002; Curran 2007).

Although there are several factors that influence physician-patient relationship, the dynamic shared and sense of trust between physicians and patients are two critical components to their overall relationship. The dynamic between physicians and patients refers to the communication patterns and the extent to which decision making is shared between both parties. Effective physician-patient communication is an integral part of clinical practice and serves as the keystone of physician-patient relationships. Studies have shown that the approach taken by physicians to communicate information is equally important as the actual information that is being communicated. When miscommunication occurs, it can have severe negative implications in clinical care such as impeding patients understanding, treatment planning and decreasing patient satisfaction of medical care. In addition to having effective communication, it is important that medical decisions stem from a collaborative process between physicians and patients. Decision making is a process in which patients should be involved 
from the very beginning and the result is a decision which reflects the physician's medical knowledge as well as the patient's values and beliefs (Lee, 2002).

Trust is a fundamental characteristic of the physician-patient relationship. Patients must trust that their physicians will work in their best interests to achieve optimal health outcomes. Studies have also shown that trust is additionally a strong predictor of a patient continuing with their health care provider. ${ }^{6}$ Trust extends to many different aspects of the physician-patient relationship including but not limited to: physician's willingness to listen to patients, patient's believing that physicians value patient autonomy and ability to make informed decisions and patients feeling comfortable enough to express and engage in dialogue related to their health concerns. The quality of relationship between doctors and patients in Government hospitals is foundational for the several outcomes as regards services rendered by doctors and those received by patients. But not much work has been done on doctor-patient relationship in Nigeria compared to other parts of the world. The main aim of this study was to identify some factors that influence the doctor-patient relationship for effective health care delivery in some health facilities in Bayelsa State, Nigeria.

\section{METHODOLOGY}

\section{Study Area}

This study was carried out in Ogbia local government area of Bayelsa state of Nigeria (south of Nigeria) in West Africa. Ogbia Town is the Headquarter of Ogbia Local Government Area in Bayelsa state. The Local Government Area has an average land area of $695 \mathrm{~km}^{2}$ and a total population of 266,008 as at 2016. English is the official language, but the major local language spoken is the Ogbia Language.

Public health facilities in Ogbia include Federal Medical Center, Otuoke, General Hospital, Kolo, Cottage Hospital, Otuasega.

\section{Study Design}

A descriptive cross-sectional study design was used to determine the some factors that influence of doctorpatient relationship on effective health care delivery in the various tertiary facilities mentioned above. A simple random sampling technique by balloting method was utilized. Patients were selected at random giving every individual an equal opportunity of being selected. The study area was structured into clinics in the various departments: Paediatrics, Obstetrics and Gynaecology, Internal medicine and surgery. A set of questionnaires was distributed to Patients who attend clinics in the various departments listed above while another set was distributed to doctors.

\section{Study Duration}

The study was carried out over a period of 3 months, consisting of time to be spent on obtaining approval, data collection, collation, analysis and report writing.

\section{Study Population}

This comprised of different categories of patients in the different public health facilities in Ogbia Local Government Area of Bayelsa State.

\section{Inclusion Criteria}

Patients (care recipients) who attend the various clinics, patient carers (both those who would respond on behalf of the patients and also those who are "potential patients" and may have had previous experiences with doctors).

\section{Exclusion criteria}

Patients who do not attend the various clinics

\section{Sample Size Determination}

Step 1: When population is greater than 10,000

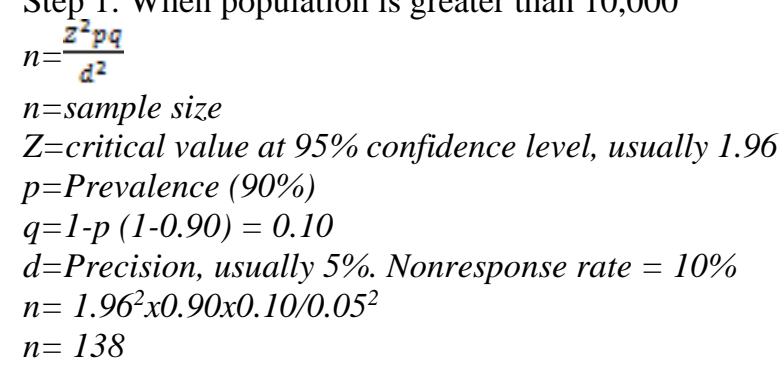

\section{Data Collection}

\section{Instrument for Data Collection:}

Semi-structured questionnaires were used to collect information on respondent's perception on the influence of doctor-patient relationship on effective healthcare delivery in Federal Medical Center, Otuoke. The questionnaires were in two forms, self-administered and the interviewer based. 


\section{Ethical Consideration}

Ethical approval for the conduct of the study was obtained from the Research and Ethics Committee of various Health Facilities respectively before commencement.

At the various clinics, verbal consent was obtained from the patients. Also, confidentiality of respondents was assured while getting their consent before recruiting them for the study.

\section{RESULTS}

The total number of questionnaires administered was 140 . Response rate was $99.5 \%$. Out of 140 questionnaires distributed, 138 were retrieved, entered and analyzed. Tables were used to represent the results from the data analysis.

Table 1 shows the Socio-demographics Profile of patients. Mean age of the patients used in the study was 30.4 years, $54.2 \%$ of the patients were within the age range of 21 -30years, the percentage of females were greater than males $(51.4 \%), 98.6 \%$ were Christians and $44.9 \%$ were civil servant, while $67.4 \%$ of them had tertiary level of education.

Table 1: Patient's Socio-demographics

\begin{tabular}{|c|c|c|}
\hline & $\begin{array}{l}\text { FREQUENCY } \\
\mathrm{n}=138\end{array}$ & $\begin{array}{l}\text { PERCENTAGE } \\
\%\end{array}$ \\
\hline \multicolumn{3}{|l|}{ Age } \\
\hline $10-20$ & 10 & 7.3 \\
\hline 21-30 & 74 & 54.2 \\
\hline 31-40 & 44 & 32.1 \\
\hline $41-50$ & 9 & 6.6 \\
\hline Total & 138 & 100 \\
\hline \multicolumn{3}{|l|}{ Sex } \\
\hline Male & 67 & 48.6 \\
\hline Female & 71 & 51.4 \\
\hline Total & 138 & 100 \\
\hline \multicolumn{3}{|l|}{ Religion } \\
\hline Christianity & 136 & 98.6 \\
\hline Islam & 1 & 0.7 \\
\hline Atheist & 1 & 0.7 \\
\hline Total & 138 & 100 \\
\hline \multicolumn{3}{|l|}{ Occupation } \\
\hline Farming & 2 & 1.4 \\
\hline Fishing & 7 & 5.1 \\
\hline Trading & 26 & 18.8 \\
\hline Civil servant & 62 & 44.9 \\
\hline Others (Student) & 41 & 29.7 \\
\hline Total & 138 & 100 \\
\hline \multicolumn{3}{|l|}{ Level of education } \\
\hline Primary & 9 & 6.5 \\
\hline Secondary & 36 & 26.1 \\
\hline Tertiary & 93 & 67.4 \\
\hline Total & 138 & 100 \\
\hline
\end{tabular}

Table 2 showed that trust, communication and language are the major factors that influence doctor-patient relationship. 
Table 2: Factors That Influence Doctor-Patient Relationship

\begin{tabular}{|c|c|c|}
\hline & FREQUENCY & PERCENTAGE \\
\hline \multicolumn{3}{|l|}{ 1.Age } \\
\hline Strongly agree & 39 & 28.3 \\
\hline Agree & 62 & 44.9 \\
\hline Neutral & 35 & 25.4 \\
\hline Disagree & 2 & 1.4 \\
\hline Total & 138 & 100 \\
\hline \multicolumn{3}{|l|}{ 2.Gender } \\
\hline Strongly agree & 27 & 19.6 \\
\hline Agree & 76 & 55.1 \\
\hline Neutral & 31 & 22.5 \\
\hline Disagree & 4 & 2.9 \\
\hline Total & 138 & 100 \\
\hline \multicolumn{3}{|c|}{ 3.Socioeconomic class } \\
\hline Strongly agree & 24 & 17.4 \\
\hline Agree & 54 & 39.1 \\
\hline Neutral & 41 & 29.7 \\
\hline Disagree & 18 & 13 \\
\hline Strongly disagree & 1 & 0.7 \\
\hline Total & 138 & 100 \\
\hline \multicolumn{3}{|l|}{ 4.Cultural belief } \\
\hline Strongly agree & 24 & 17.4 \\
\hline Agree & 47 & 34.1 \\
\hline Neutral & 36 & 26.1 \\
\hline Disagree & 29 & 21 \\
\hline Strongly disagree & 2 & 1.4 \\
\hline Total & 138 & 100 \\
\hline \multicolumn{3}{|l|}{ 5.Level of education } \\
\hline Strongly agree & 46 & 33.3 \\
\hline Agree & 60 & 43.5 \\
\hline Neutral & 23 & 16.7 \\
\hline Disagree & 8 & 5.8 \\
\hline Strongly disagree & 1 & 0.7 \\
\hline Total & 138 & 100 \\
\hline \multicolumn{3}{|l|}{ 6.Trust } \\
\hline Strongly agree & 69 & 50 \\
\hline Agree & 58 & 42 \\
\hline Neutral & 11 & 8 \\
\hline \multicolumn{3}{|l|}{ Disagree } \\
\hline \multicolumn{3}{|l|}{ Strongly disagree } \\
\hline Total & 138 & 100 \\
\hline \multicolumn{3}{|l|}{ 7.Communication } \\
\hline Strongly agree & 73 & 52.9 \\
\hline Agree & 54 & 39.1 \\
\hline Neutral & 10 & 7.2 \\
\hline Disagree & 1 & 0.7 \\
\hline \multicolumn{3}{|l|}{ Strongly disagree } \\
\hline Total & 138 & 100 \\
\hline
\end{tabular}




\begin{tabular}{lll}
\hline 8.Language & 56 & 40.6 \\
Strongly agree & 71 & 51.4 \\
Agree & 9 & 6.5 \\
Neutral & 2 & 1.4 \\
Disagree & & \\
Strongly disagree & 138 & 100 \\
Total & & \\
& & \\
9.Access to healthcare/available healthcare & & 21 \\
systems & 29 & 36.2 \\
Strongly agree & 50 & 22.5 \\
Agree & 31 & 18.1 \\
Neutral & 25 & 2.2 \\
Disagree & 3 & 100 \\
Strongly disagree & 138 & \\
Total & & \\
\hline
\end{tabular}

Table 3: Age as at last birthday Versus Does your doctor explain the treatment chosen in clear terms? Does your doctor explain the treatment chosen in clear terms?

\begin{tabular}{|c|c|c|c|c|c|c|c|}
\hline & & Always & Often & Sometimes & Rarely & Never & Total \\
\hline \multicolumn{8}{|c|}{$\begin{array}{l}\text { How old are you as at your last } \\
\text { birthday }\end{array}$} \\
\hline \multirow[t]{2}{*}{$10-20$} & Frequency & 4 & 2 & 2 & 2 & 0 & 10 \\
\hline & Percentage & $2.9 \%$ & $1.5 \%$ & $1.5 \%$ & $1.5 \%$ & 0 & $7.4 \%$ \\
\hline \multirow[t]{2}{*}{ 21-30years } & Frequency & 24 & 20 & 18 & 20 & 0 & 82 \\
\hline & Percentage & $17.5 \%$ & $14.6 \%$ & $13.1 \%$ & $14.6 \%$ & 0 & $59.8 \%$ \\
\hline \multirow[t]{2}{*}{ 31-40years } & Frequency & 18 & 5 & 15 & 5 & 2 & 45 \\
\hline & Percentage & $13.1 \%$ & $3.6 \%$ & $10.9 \%$ & $3.6 \%$ & 1.5 & $31.2 \%$ \\
\hline \multirow[t]{2}{*}{ 41-50years } & Frequency & 1 & 2 & 2 & 2 & 0 & 7 \\
\hline & Percentage & $0.7 \%$ & $1.5 \%$ & $1.5 \%$ & $1.5 \%$ & 0 & $5.2 \%$ \\
\hline \multirow[t]{2}{*}{ Total } & Frequency & 47 & 29 & 37 & 29 & 2 & $138 \mathrm{t}$ \\
\hline & Percentage & $34.3 \%$ & $21.2 \%$ & $27.0 \%$ & $21.2 \%$ & 1.5 & $100 \%$ \\
\hline
\end{tabular}

Table 4: Level Of Education Versus Does Your Doctor Explains The Treatment Chosen In Clear Terms?

\begin{tabular}{|c|c|c|c|c|c|c|c|}
\hline \multicolumn{8}{|c|}{ Level of education * Does your doctor explains the treatment chosen in clear terms? Cross-tabulation } \\
\hline \multirow[t]{2}{*}{ Level of education } & & \multicolumn{5}{|c|}{$\begin{array}{l}\text { Does your doctor explain the treatment chosen in } \\
\text { clear terms? }\end{array}$} & \multirow[t]{2}{*}{ Total } \\
\hline & & never & rarely & sometimes & Often & always & \\
\hline \multirow[t]{2}{*}{ Primary } & frequency & 0 & 5 & 1 & 1 & 2 & 9 \\
\hline & percentage & $0.0 \%$ & $3.6 \%$ & $0.7 \%$ & $0.7 \%$ & $1.4 \%$ & $6.5 \%$ \\
\hline \multirow[t]{2}{*}{ Secondary } & frequency & 0 & 6 & 9 & 7 & 14 & 36 \\
\hline & percentage & $0.0 \%$ & $4.3 \%$ & $6.5 \%$ & $5.1 \%$ & $10.1 \%$ & $26.1 \%$ \\
\hline \multirow[t]{2}{*}{ Tertiary } & frequency & 2 & 11 & 28 & 21 & 31 & 93 \\
\hline & percentage & $1.4 \%$ & $8.0 \%$ & $20.3 \%$ & $15.2 \%$ & $22.5 \%$ & $67.4 \%$ \\
\hline \multirow[t]{2}{*}{ Total } & frequency & 2 & 22 & 38 & 29 & 47 & 138 \\
\hline & percentage & $1.4 \%$ & $15.9 \%$ & $27.5 \%$ & $21.0 \%$ & $34.1 \%$ & $100.0 \%$ \\
\hline
\end{tabular}

The table above showed that $67.4 \%$ of respondent with tertiary level of education agreed that their doctors explain the treatment chosen in clear terms. 
Table 5: Level of Education Versus Does Your Doctor Explain Things Concerning Your Health Problem In Clear And Complete Terms?

\begin{tabular}{cllllllll}
\hline Level of education & \multicolumn{6}{l}{$\begin{array}{l}\text { Does your doctor explain things concerning your health problem in } \\
\text { clear and complete terms? }\end{array}$} & Total \\
& & never & rarely & sometimes & Often & always & \\
\hline \multirow{2}{*}{ Primary } & Frequency & 0 & 0 & 4 & 3 & 2 & 9 \\
& Percentage & $0.0 \%$ & $0.0 \%$ & $2.9 \%$ & $2.2 \%$ & $1.4 \%$ & $6.5 \%$ \\
Secondary & Frequency & 0 & 1 & 7 & 9 & 19 & 36 \\
& Percentage & $0.0 \%$ & $0.7 \%$ & $5.1 \%$ & $6.5 \%$ & $13.8 \%$ & $26.1 \%$ \\
\multirow{5}{*}{ Tertiary } & Frequency & 1 & 0 & 26 & 29 & 37 & 93 \\
& Percentage & $0.7 \%$ & $0.0 \%$ & $18.8 \%$ & $21.0 \%$ & $26.8 \%$ & $67.4 \%$ \\
Total & Frequency & 1 & 1 & 37 & 41 & 58 & 138 \\
& Percentage & $0.7 \%$ & $0.7 \%$ & $26.8 \%$ & $29.7 \%$ & $42.0 \%$ & $100.0 \%$ \\
\hline
\end{tabular}

\section{DISCUSSION}

There are several factors that influence physician-patient relationship such as age, gender, level education, socioeconomic class, communication, trust, access to health care services, religious beliefs and cultural beliefs but two critical components that greatly influenced the doctor-patient relative for effective health care delivery in our research were communication patterns (dynamic shared) and sense of trust.

\section{Dynamic between physicians and patients}

The dynamic between physicians and patients refers to the communication patterns and the extent to which decision making is shared between both parties. Effective physician-patient communication is an integral part of clinical practice and serves as the keystone of physician-patient relationships. Studies have shown the approach taken by physicians to communicate information is equally important as the actual information that is being communicated. This type of communication incorporates both verbal and non-verbal interactions between physicians and patients (Lee, 2002). Effective communication has been shown to influence a wide array of outcomes including emotional health, symptoms resolution, function, pain control and physiologic measures such as blood pressure levels. When miscommunication occurs, it can have severe negative implications in clinical care such as impeding patient understanding, expectations of treatment, treatment planning, decreasing patient satisfaction of medical care and reducing levels of patient hopefulness (Stewart, 1995).

In addition to having effective communication, it is important that medial decisions stem from a collaborative process between physicians and patients. Decision making is a process in which patients should be involved in from the very beginning, and the result is a decision which reflects the physician's medical knowledge as well as the patient's values and beliefs. ${ }^{18}$ Collaborative communication and decision making have been correlated with greater patient satisfaction and loyalty. Working from a collaborative framework along with effective physician patient communication can also strengthen a physician's ability to utilize a personalized health care model through patient empowerment.

\section{Trust between physician and patients}

Trust is a fundamental characteristic of the physician-patient relationship. Patients must trust that their physicians will work in their best interest to achieve optimal health outcomes. Patients' trust in their physicians has been demonstrated to be more important than treatment satisfaction in predictions of patient adherence to recommendations and their overall satisfaction with care (Lee, 2002). Studies have also shown that trust is additionally a strong predictor of a patient continuing with their provider (Stewart, 1995). Trust extends to many different aspects of the physician-patient relationships including, but not limited to: physicians' willingness to listen to patients, patients' believing that physicians value patient autonomy and ability to make informed decisions and patients feeling comfortable enough to express and engage in dialogue related to their health concerns (Nazione et al., 2019).

Effective physician-patient communication has been shown to positively influence health outcomes by increasing patient satisfaction, leading to greater patient understanding of health problems and treatments 
available, contributing to better adherence to treatment plans and providing support and reassurance to patients. Trust within all areas of the physician-patient relationship is a critical factor that influences communication between both parties. As health care transforms into a more personalized and patient-centered model, the physician-patient relationship will significantly shape health outcomes. The idea of viewing physician-patient relationship as a core element of quality health care is not something new, however understanding and assessing the factors that influence this relationship is just the beginning. By understanding the factors that influence patient-physician relationships, in the future, health care providers will be able to address some of the barriers that prevent the adoption of more personalized approaches to health care. This study will help us to identify other factors that influence this relationship.

Tongue et al 2005, demonstrated that in an extensive national survey conducted by American academy of orthopaedic surgeons (AAOS) with 807 patients and 700 orthopaedic surgeons show that $75 \%$ of orthopaedic surgeons survey believed that they communicate satisfactorily with their patients but only $21 \%$ of the patients reported satisfactory communication with their doctor results from our study also showed both doctors and patients agreed that communication and trust is one of the major factors that influences doctor patient relationship.

\section{CONCLUSION}

Although several factors influence the physician-patient relationship, many of the patients were satisfied with the level of Doctor-Patient relationship with communication and trust playing the most important roles in this relationship.

\section{REFERENCES}

1. Curran, James (1 November 2007). "The Doctor, his Patient and the Illness". BMJ. 335 (7626): 941.2-941. doi:10.1136/bmj.39384.467928.94. ISSN 0959-8138. PMC 2048858.

2. Dwolatzky, T., Dwolatzky, Clarfield, A. M., \& Clarfield. (2006). Doctor-Patient Relationships. In R. Schulz, Encyclopedia of aging (4th ed.). Springer Publishing Company.

3, Helin T (2002). The Physician-Patient relationship; recent development and changes. Hemophilia, 8 (2002), pp. $450-454$

4. John R. Tongue, Howard, E. Epps and Laura,L. Forese (2005). Journal of Bone and Joint Surgery. Volume 8, number 3, pp652-658.

5. Lee, S. J., Back, A. L., Block, S. D., \& Stewart, S. K. (2002, January 1). Enhancing physicianpatient communication. Retrieved from https://www.ncbi.nlm.nih.gov/pubmed/12446437

6, Nazione, Samantha; Perrault, Evan K.; Keating, David M. (22 May 2019). "Finding Common Ground: Can Provider-Patient Race Concordance and Self-disclosure Bolster Patient Trust, Perceptions, and Intentions?". Journal of Racial and Ethnic Health Disparities. 6 (5): 962-972. doi:10.1007/s40615-019-00597-6. ISSN 21973792.

7. Stewart, M. A. (1995, May 01). Effective physician patient communication and health outcomes: A review. Retrieved from https://www.ncbi.nlm.nih.gov/pubmed/7728691

8. Szasz T. Hollender M. A contribution to the philosophy of medicine: the basic model of the doctor-patient relationship Arch Int Med, 97 (1956), pp. 585-592. 